\title{
Type 2 Valvular Heart Disease Affects Decision Making for Anticoagulation in Patients with Atrial Fibrillation: The UMBRIA-Fibrillazione Atriale Prospective Study
}

\author{
Maria Cristina Vedovati ${ }^{1}$ Gianpaolo Reboldi ${ }^{2}$ Giancarlo Agnelli ${ }^{1}$ Paolo Verdecchia ${ }^{3}$ on Behalf of the
} Umbria-Fibrillazione Atriale Investigators*

${ }^{1}$ Vascular and Emergency Medicine - Stroke Unit, University of
Perugia, Perugia, Italy
2 Department of Medicine, University of Perugia, Perugia, Italy
${ }^{3}$ Fondazione Umbra Cuore e Ipertensione-ONLUS, Ospedale S. Maria
Della Misericordia, Perugia, Italy

TH Open 2019;3:e157-e164.

\begin{abstract}
Address for correspondence Maria Cristina Vedovati, MD, Vascular and Emergency Medicine - Stroke Unit, University of Perugia, Via G Dottori 1, 06129 Perugia, Italy (e-mail: mc.vedovati@gmail.com).
\end{abstract}

\begin{abstract}
Keywords

- atrial fibrillation

- valvular heart disease

- vitamin K antagonists

- non-vitamin K oral anticoagulants

Background Valvular heart disease (VHD) and atrial fibrillation (AF) often coexist. Aim We investigated whether type 2 VHD (other than moderate-severe rheumatic mitral stenosis or mechanical heart valve) influences the prescription of anticoagulants in AF.

Methods Umbria-Fibrillazione Atriale is a prospective multicenter registry in patients with AF. For the purpose of this study, type 2 VHD patients were propensity matched with non-VHD counterparts in a 1:1 ratio. Patients with type $1 \mathrm{VHD}$ (moderate-severe mitral stenosis or mechanical heart valve) were excluded.

Results We identified 2,212 patients with AF and excluded 46 because data on VHD were unavailable. Type $2 \mathrm{VHD}$ was present in 426 patients (19.7\%). Before registry entry visit, $77.1 \%$ of type 2 VHD and $66.8 \%$ of non-VHD patients were on anticoagulants. At discharge, 90.8 and $85.2 \%$ of patients, respectively, were on anticoagulants. After propensity-score matching, 386 patient-pairs were created. In the matched sample, the likelihood of being on anticoagulants before (odds ratio [OR]: $1.43,95 \%$ confidence interval $[\mathrm{Cl}]: 1.02-2.01, p=0.036)$ and after $(1.63,95 \% \mathrm{Cl}: 1.04-2.57, p=0.034)$ the entry visit was higher in type $2 \mathrm{VHD}$ than in non-VHD patients. Patients with type $2 \mathrm{VHD}$ were $70 \%$ more likely to receive vitamin $\mathrm{K}$ antagonists (VKAs) (OR: $1.70,95 \% \mathrm{Cl}: 1.28-$ 2.27, $p<0.001$ ), and $32 \%$ less likely to receive non-vitamin $\mathrm{K}$ oral anticoagulants (NOACs; OR: $0.68,95 \% \mathrm{Cl}: 049-0.94, p=0.011$ ) than non-VHD patients.

Conclusion VKAs consistently outperformed NOACs as preferred treatment option in patients with type 2 VHD. This could potentially deny to these patients the wellestablished benefits of NOACs observed in phase III trials.
\end{abstract}

\section{Introduction}

Valvular heart disease (VHD) and atrial fibrillation (AF) are frequent conditions which generally share an enlargement of the left atrium in addition to several risk factors such as

-Appendix A lists all the Umbria-Fibrillazione Atriale Investigators. advanced age, hypertension, diabetes, coronary heart disease, and heart failure. ${ }^{1}$ Both AF and VHD are independent risk factors for stroke and systemic embolism. ${ }^{2}$ VHD is associated with a higher risk of thromboembolism regardless of the underlying cardiac rhythm. ${ }^{3}$ When $\mathrm{AF}$ and rheumatic mitral stenosis coexist, the thromboembolic risk is particularly high., ${ }^{4,5}$

(c) 2019 Georg Thieme Verlag KG Stuttgart · New York
License terms

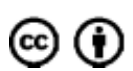

September 18, 2018

accepted

April 24, 2019
DOI https://doi.org/

10.1055/s-0039-1692202.

ISSN 2512-9465. 
Management strategies for patients with AF in association with VHD have been less informed by recent randomized trials comparing vitamin Kantagonists (VKAs) to non-vitamin Koral anticoagulants (NOACs). Patients with AF and moderate or severe mitral stenosis or mechanical prosthetic valves are at very high risk of thromboembolic events ( $25 \%$ per year if not anticoagulated and $\sim 0.8 \%$ per year if treated with anticoagulants ${ }^{4}$ ), and therefore their random allocation to drugs different from VKAs was considered unethical. A trial specifically conducted with dabigatran versus VKAs in patients with $\mathrm{AF}$ and mechanical heart valves (RE-ALIGN) was prematurely interrupted because of an excess in thromboembolic and bleeding complications in the dabigatran group. ${ }^{6}$

Definition and staging of the underlying VHD in patients with AF may affect the anticoagulation strategy. A recent Evaluated Heartvalves, Rheumatic or Artificial (EHRA) Consensus Document proposed a categorization in relation to the type of oral anticoagulant to be preferred in patents with $\mathrm{AF}$ and VHD. ${ }^{7}$ The type 1 VHD refers to AF patients who require therapy with VKAs and includes patients with mitral stenosis (moderate/severe of rheumatic origin) or mechanical prosthetic valve replacement, whereas the type 2 VHD (all other types of VHD) refers to AF patients who require either VKAs or NOACs. The indication to anticoagulation in EHRA type 2 VHD should also take into consideration the thromboembolic risk according to the $\mathrm{CHA}_{2} \mathrm{DS}_{2}$-VASc score. ${ }^{7}$

Subgroup analyses of phase III trials of NOACs in patients with AF showed that those with type 2 VHD were older, had more comorbidities including renal dysfunction, and were more frequently affected by persistent or permanent AF than patients without VHD. ${ }^{7,8}$ Patients with type 2 VHD had higher cardioembolic and bleeding risk scores than patients without VHD. ${ }^{7,8}$ Furthermore, irrespective of the treatment (i.e., VKAs or NOACs), type 2 VHD patients experience a worse outcome (stroke and systemic embolism, major bleeding, or all-cause death) in comparison to non-VHD patients. ${ }^{7,8}$

In the daily practice, despite the lack of evidence from clinical trials, type 2 VHD generally is perceived as a condition of increased thromboembolic risk, thus conditioning the choice of anticoagulant treatment. This could lead to denying these patients the benefits of NOACs versus VKAs found in controlled trials. ${ }^{9,10}$ The present study was designed to evaluate whether diagnosis of type 2 VHD influences prescription and choice of anticoagulants in patients with $\mathrm{AF}$ in real life.

\section{Methods}

We included in this analysis patients enrolled in the "Umbria-Fibrillazione Atriale" study from January 2013 to December 2017. The "Umbria-Fibrillazione Atriale" study (www.umbriafa.it), established in 2013, is an ongoing observational registry in patients with AF. Patients are being recruited from 22 centers in Umbria, Italy. Study centers include cardiology, internal medicine, or neurology hospital units or outpatient facilities. Admission criteria include all the following: diagnosis of AF and at least one episode of AF diagnosed by electrocardiography within 1 year before the date of admission. Exclusion criteria are the presence of mechanical heart valves, moderate or severe mitral stenosis, a live expectancy less than 1 year, or refusal of informed consent. Baseline data on risk factors and treatment strategies in use before and after the registry entry visit are stored in a clinical web-based record form (www.umbriafa.it), with access protected by personal passwords. The patients undergo regular follow-up visits by their family doctors and/or hospital staff to ascertain their clinical status, adherence to treatment and occurrence of side effects, and major cardiovascular complications.

The informed consent is obtained from each patient and the study protocol conforms to the ethical guidelines of the 1975 Declaration of Helsinki as reflected in a priori approval by Ethical Committee and/or Institutional Review Boards of the participating centers.

This study was designed to evaluate whether diagnosis of type 2 VHD influences prescription and choice of anticoagulants in patients with $\mathrm{AF}$ in real life.

The following data are collected at the entry visit: age, gender, weight, height, smoke or alcohol assumption, symptoms, blood pressure, heart rate, and comorbidities. These include hypertension, congestive heart failure, diabetes, previous stroke or transient ischemic stroke or systemic embolism, vascular disease, peripheral artery disease, renal or liver disease, previous bleeding, cancer, chronic obstructive pulmonary disease, type of $\mathrm{AF}$ (paroxysmal, persistent, permanent), presence of pacemaker or intracardiac defibrillator, electrocardiographic and echocardiographic findings, presence of type 2 VHD, previous cardioversion/ablation, and laboratory tests (platelet number, hemoglobin level, and creatinine value). Treatments in use before and after the registry entry visit are also collected. Antithrombotic strategies are categorized as follows: none, antiplatelet agents, low-molecular-weight heparin, VKAs, or NOACs.

For the purpose of this study, congestive heart failure, renal and liver failure, and vascular diseases are defined according to the $\mathrm{CHA}_{2} \mathrm{DS}_{2}$-VASc and HAS-BLED criteria, as reported in a previous study. ${ }^{11}$

Type 2 VHD was defined as moderate or severe mitral or aortic regurgitation, moderate or severe aortic stenosis, or mild mitral stenosis (mitral valve area $>2.0 \mathrm{~cm}^{2}$ on standard echocardiography).

The primary outcome of this analysis was the use of anticoagulant treatment as reported before and at the end of the registry entry visit in type 2 VHD and in non-VHD patients. Anticoagulant treatment was defined as the use of low-molecular-weight heparin, VKAs, or NOACs.

Data analysis was performed using SAS/STAT Rel. 9.4 (http://www.sas.com) and R version 3 (http://www.rproject.org), and statistical significance was defined as a twosided $p$-value less than 0.05 . The propensity scores (PSs) for VHD status were estimated from a logistic regression model which included the following covariables: age, gender, type of AF, hypertension, diabetes, congestive heart failure, vascular disease, previous stroke or transient ischemic attack or systemic embolism, history of bleeding, severe renal failure, liver failure, and history of cancer. Type 2 VHD patients were 
matched in a 1:1 ratio with non-VHD patients, and balance was assessed using standardized differences with limits of -0.1 and $0.1 .^{12,13}$

Categorical data were reported as frequencies and continuous data as mean \pm SD. Continuous data were compared with the use of $t$-test and categorical data were compared with the use of $\chi^{2}$ test.

The likelihood of the use of anticoagulant treatment before and after the registry entry visit in type 2 VHD patients and in non-VHD patients was reported as odds ratios with $95 \%$ confidence intervals (CIs). Subgroup analyses were also set for mitral or aortic site of type 2 VHD and for type of anticoagulant (VKAs or NOACs).

\section{Results}

Overall, 2,212 patients with AF were evaluated and 46 were excluded because data on VHD were not available. Type 2 VHD was present in $426(19.7 \%)$ of the 2,166 patients included in the analysis (-Fig. 1).

Compared with non-VHD patients, those with type 2 VHD were older, had a higher prevalence of kidney and liver disease, and had higher thrombotic and bleeding risk scores. Patients' baseline characteristics according to VHD status are shown in - Table 1.

At registry entry visit, anticoagulant treatment was being used by 77.0 and $66.8 \%$ of type 2 VHD and non-VHD patients $(p<0.001$ ), respectively (-Fig. 2). VKAs were more frequently used in type 2 VHD compared with non-VHD patients: 53.9 versus $40.8 \%$ ( $p<0.001$ ), while NOACs were used in $9.2 \%$ type 2 VHD and in $13.4 \%$ non-VHD patients $(p=0.020)$. No significant differences were observed in the use of low-molecular-weight heparins (13.9\% in type 2 VHD and $12.6 \%$ in non-VHD, $p=0.473$ ) and of antiplatelet agents between the two groups ( $11.6 \%$ in type 2 VHD and $13.3 \%$ non-
VHD, $p=0.336$ ). The remaining 11.4 and $19.9 \%$ of type 2 VHD and non-VHD patients $(p<0.001)$ were on no antithrombotic treatment.

At visit discharge, 90.8 and $85.2 \%$ of patients with type 2 VHD and non-VHD ( $p=0.002)$, respectively, were on anticoagulant treatment. The proportion of patients on anticoagulant treatment increased after the entry visit, but numerically less in type 2 VHD (5.6\%) than in non-VHD (10.3\%) patients. At visit discharge, VKAs were more frequently used in type 2 VHD compared with non-VHD patients: 54.4 versus $41.1 \%$, respectively ( $p<0.001$ ). NOACs were in use in $23.1 \%$ of type 2 VHD and in $32.4 \%$ of non-VHD patients $(p<0.001)$. Low-molecular-weight heparins $(13.4 \%$ of type 2 VHD and in $11.7 \%$ of non-VHD patients, $p<0.327$ ) and antiplatelet agents (in $3.3 \%$ of type 2 VHD and in $4.8 \%$ of non-VHD, $p=0.171$ ) were similarly used among the two groups. The remaining 5.9 and $10.0 \%$ of patients $(p=0.009$ ), of the two groups respectively, were on no antithrombotic treatment at visit discharge.

\section{Propensity Score-Matched Cohort}

After PS matching, 386 patient-pairs were formed. No differences were observed in patients with and without VHD after matching (-Fig. 3). Treatment prescription according to the presence of type 2 VHD is reported in - Fig. 4.

In the matched populations, the likelihood of anticoagulant treatment before and after the registry entry visit was consistently higher in patients with type 2 VHD than in nonVHD: 77.0 versus $71.0 \%$; odds ratio (OR): $1.43,95 \% \mathrm{CI}: 1.02-$ $2.01, p=0.036$, before and 90.9 versus $86.0 \%$; OR: $1.63,95 \%$ CI: 1.04-2.57, $p=0.034$, after, respectively. Type 2 VHD patients were more likely to receive VKAs (54.7 vs. $41.2 \%$, OR: $1.70,95 \% \mathrm{CI}: 1.28-2.27, p<0.001)$ and less likely to receive NOACs (23.0 vs. $30.8 \%$, OR: $0.68,95 \%$ CI: $0.49-0.94$, $p=0.011$ ) when compared with non-VHD (-Table 2).

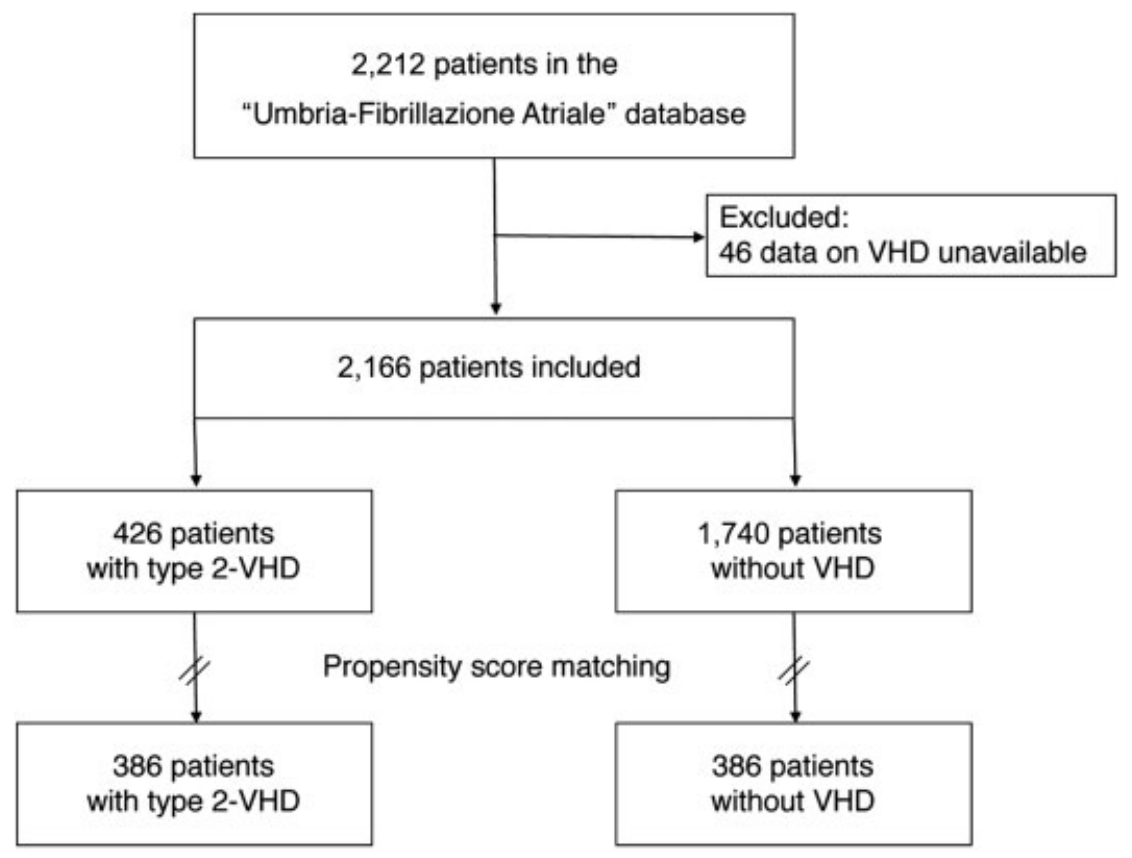

Fig. 1 Flow diagram of the study population. VHD, valvular heart disease. 
Table 1 Patients' characteristics

\begin{tabular}{|c|c|c|c|c|}
\hline & & \multicolumn{2}{|c|}{ Overall population } & \multirow[t]{2}{*}{$p$-Value } \\
\hline & & Non-VHD & Type 2 VHD & \\
\hline Patients, $N$ & & 1,740 & 426 & \\
\hline Age, mean (SD) & & $74.9(11)$ & $78.2(9)$ & $<0.001$ \\
\hline \multirow[t]{2}{*}{ Gender, $N(\%)$} & Female & $755(43)$ & $206(48)$ & \multirow[t]{2}{*}{0.064} \\
\hline & Male & $985(56)$ & $220(52)$ & \\
\hline \multirow[t]{2}{*}{ Patterns of atrial fibrillation, $N(\%)$} & First diagnosed/paroxysmal & $578(33)$ & $117(27)$ & \multirow[t]{2}{*}{$<0.001$} \\
\hline & Persistent/permanent & $1,147(66)$ & $309(73)$ & \\
\hline $\mathrm{CHADS}_{2}$, mean (SD) & & $2.1(1.3)$ & $2.5(1.3)$ & $<0.001$ \\
\hline $\mathrm{CHA}_{2} \mathrm{DS}_{2} \mathrm{VASc}$, mean (SD) & & $3.6(1.8)$ & $4.3(1.7)$ & $<0.001$ \\
\hline HAS-BLED, mean (SD) & & $1.5(1.0)$ & $1.7(1.0)$ & $<0.001$ \\
\hline \multirow[t]{2}{*}{ Hypertension, $N(\%)$} & No & $351(20)$ & $60(14)$ & \multirow[t]{2}{*}{0.004} \\
\hline & Yes & $1,382(80)$ & $366(86)$ & \\
\hline \multirow[t]{2}{*}{ Diabetes, $N(\%)$} & No & $1,395(81)$ & $338(79)$ & \multirow[t]{2}{*}{0.59} \\
\hline & Yes & $338(19)$ & $88(21)$ & \\
\hline \multirow[t]{2}{*}{ Congestive heart failure, $N(\%)$} & No & $1,441(82)$ & $263(62)$ & \multirow[t]{2}{*}{$<0.001$} \\
\hline & Yes & $292(17)$ & $163(38)$ & \\
\hline \multirow[t]{2}{*}{ Vascular disease, $N(\%)$} & No & $1,335(77)$ & $275(65)$ & \multirow[t]{2}{*}{$<0.001$} \\
\hline & Yes & $398(23)$ & $151(35)$ & \\
\hline \multirow[t]{2}{*}{ Previous stroke/TIA/SE, $N(\%)$} & No & $1,411(81)$ & $334(78)$ & \multirow[t]{2}{*}{0.16} \\
\hline & Yes & $322(19)$ & $92(22)$ & \\
\hline \multirow[t]{2}{*}{ History of bleeding, $N(\%)$} & No & $1,662(95)$ & $399(94)$ & \multirow[t]{2}{*}{0.11} \\
\hline & Yes & $78(4)$ & $27(6)$ & \\
\hline \multirow[t]{2}{*}{ Severe renal disease, $N(\%)$} & No & $1,676(97)$ & $394(92)$ & \multirow[t]{2}{*}{$<0.001$} \\
\hline & Yes & $57(3)$ & $32(7)$ & \\
\hline \multirow[t]{2}{*}{ Liver disease, $N(\%)$} & No & $1,722(99)$ & $416(98)$ & \multirow[t]{2}{*}{0.032} \\
\hline & Yes & $18(1)$ & $10(2)$ & \\
\hline \multirow[t]{2}{*}{ History of cancer, $N(\%)$} & No & $1,573(90)$ & $379(89)$ & \multirow[t]{2}{*}{0.374} \\
\hline & Yes & $167(10)$ & $47(11)$ & \\
\hline
\end{tabular}

Abbreviations: SE, systemic embolism; TIA, transient ischemic attack; VHD, valvular heart disease.

\section{Treatment Use According to Valvular Defect}

Among patients with type 2 VHD, the majority (313; 73.5\%) had mitral regurgitation, while 163 (38.3\%) had aortic regurgitation, 111 (26.1\%) had aortic stenosis, and 28 (6.6\%) had mild mitral stenosis. Before and after the referral visit, no significant differences in the use of anticoagulants were found among the various type 2 VHDs. The use of VKAs was preferred at visit discharge in patients with mild mitral stenosis compared with other type 2 VHDs, but the difference did not reach formal statistical significance (69 vs. $50 \%$, $p=0.072$ ).

One-hundred and fifty-nine patients (37.3\%) had more than one valvular defect. Type 2 VHD at aortic site was present in 112 patients (26.3\%), at mitral site in 181 (42.5\%), and was combined in the remaining 133 patients (31.2\%).

The probability to receive an anticoagulant treatment in patients with one valvular defect was similar to those with two or more defects both before the visit (77.4 vs. $76.6 \%$, $p=0.854)$ and at discharge (92.5 vs. 91.9\%, $p=0.837$ ). Similarly, in patients with aortic, mitral, and combined valvular defect, no significant differences in terms of anticoagulant use were observed before the visit $(77.5,77.2$, and $76.5 \%$, respectively, $p=0.982$ ) as well as at discharge (95.3, 91.2 , and $91.1 \%$, respectively, $p=0.395$ ).

\section{Discussion}

In the Umbria-Fibrillazione Atriale study, the overall proportion of patients on anticoagulants is currently nearly $90 \%$ at discharge. Besides a prevalence of anticoagulation somewhat higher than that observed in other studies, ${ }^{14}$ the novel finding of our study is the lack of influence of type 2 VHD as determinant of the overall use of anticoagulants. We further found, however, that patients with type 2 VHD were $70 \%$ more likely to receive VKAs, and 32\% less likely to receive NOACs, when compared with patients without 


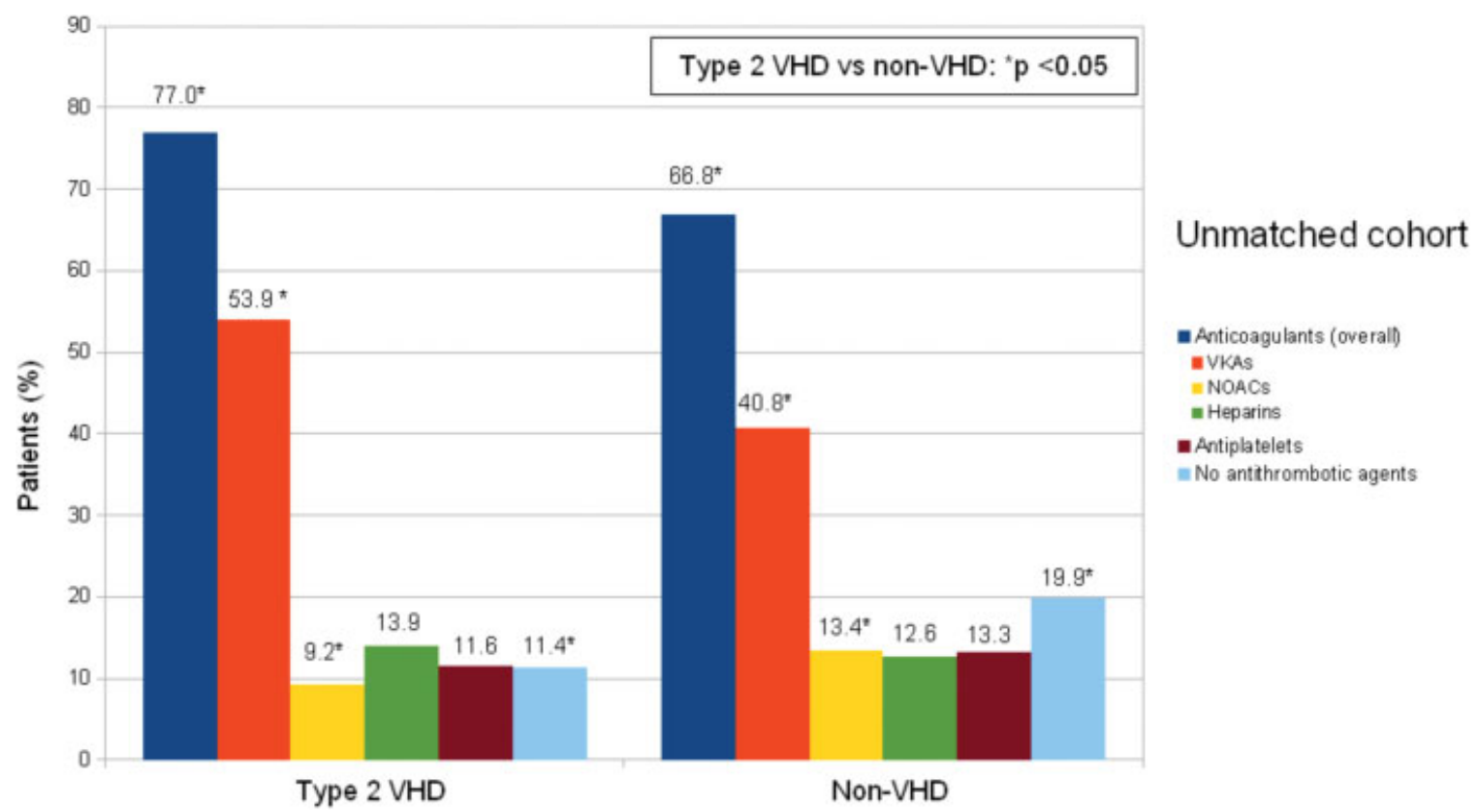

Fig. 2 Treatment distribution in type 2 VHD and in non-VHD unmatched patients at entry visit. VHD, valvular heart disease

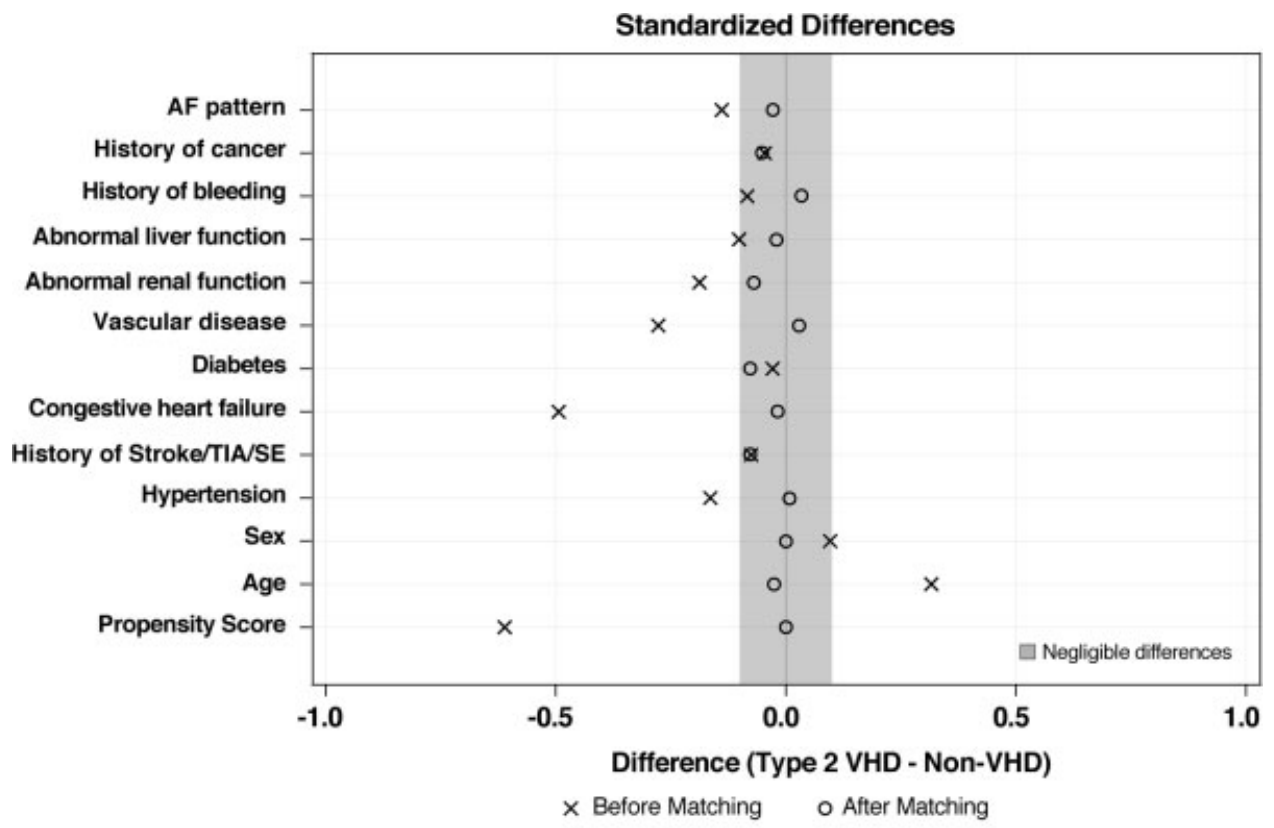

Fig. 3 Standardized mean differences plot before and after matching. All differences for the matched observations are within the balance limits of -0.1 and 0.1 which are indicated by the shaded area. AF, atrial fibrillation; SE, systemic embolism; TIA, transient ischemic attack; VHD, valvular heart disease.

VHD. The two groups of patients were well characterized and matched by PS, which allowed for a reliable comparison between the groups. Thus, our physicians seem to be actually more reluctant to prescribe NOACs, and more inclined to maintain or prescribe VKAs, in these patients. A possible explanation is that the presence of type 2 VHD is perceived as a condition of increased thromboembolic risk, thus conditioning the choice of anticoagulant treatment. It will be important to verify whether the recent indication of not considering VKAs as a priority option in patients with type 2 $\mathrm{VHD}^{7}$ will impact on such attitude in the next future.
In a study from Turkey, Basaran at al addressed the issue of treatment strategies in patients with AF and VHD different from mitral stenosis or prosthetic heart valves. ${ }^{15}$ In that study, $73.8 \%$ of patients with type 2 VHD were on oral anticoagulants, as opposed to $71.2 \%$ of patients without VHD ( $p=0.035)$. Treatment with VKAs was more prevalent in patients with type 2 VHD than in those without VHD (37 vs. $32.9 \%, p=0.002$ ), while NOACs were equally distributed between the two groups ( $37 \mathrm{vs.}$ $38 \%, p=0.324)$. In the study by Basaran et al, mitral regurgitation was the most prevalent type of VHD, followed by aortic regurgitation and aortic stenosis. Overall, the use of 


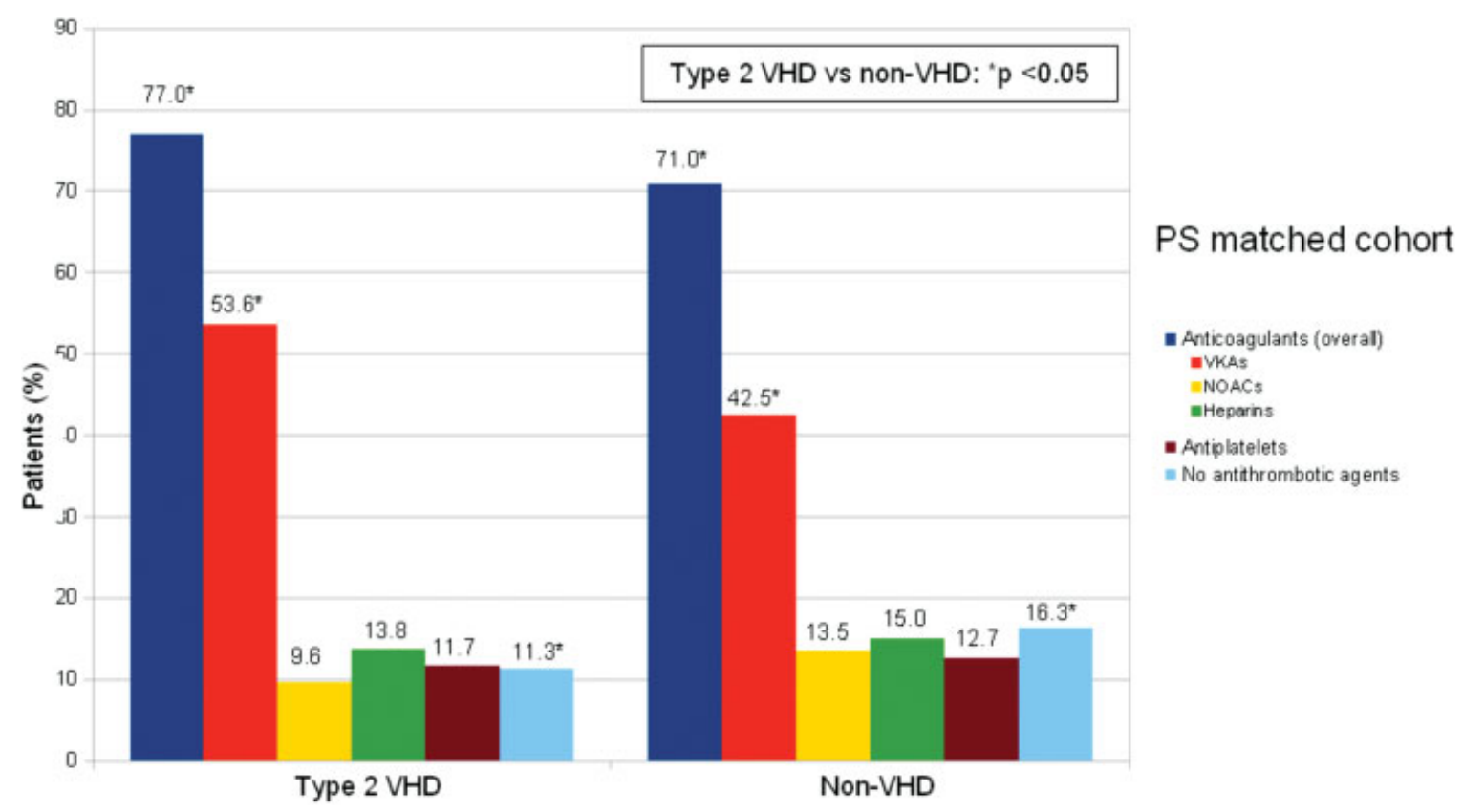

Fig. 4 Treatment distribution in type 2 VHD and in non-VHD matched patients at entry visit. PS, propensity score; VHD, valvular heart disease.

Table 2 Anticoagulants use before and after the registry entry visit in the propensity-matched sample

\begin{tabular}{|c|c|c|c|c|c|}
\hline \multirow[t]{2}{*}{ Treatment } & & \multicolumn{2}{|l|}{ At entry } & \multicolumn{2}{|c|}{ At discharge } \\
\hline & & $N, \%$ & OR (95\% Cl, p-value) & $N, \%$ & OR (95\% Cl, p-value) \\
\hline \multirow[t]{2}{*}{ Any anticoagulant } & Type 2 VHD & $297,77.0$ & \multirow[t]{2}{*}{$1.43(1.02-2.01,0.036)$} & $351,90.9$ & \multirow[t]{2}{*}{$1.63(1.04-2.57,0.034)$} \\
\hline & Non-VHD & $274,71.0$ & & $332,86.0$ & \\
\hline \multirow[t]{2}{*}{ VKAs } & Type 2 VHD & $207,53.6$ & \multirow[t]{2}{*}{$1.58(1.19-2.12,0.002)$} & $211,54.7$ & \multirow[t]{2}{*}{$1.70(1.28-2.27,<0.001$} \\
\hline & Non-VHD & $164,42.5$ & & $159,41.2$ & \\
\hline \multirow[t]{2}{*}{ NOACs } & Type 2 VHD & $37,9.6$ & \multirow[t]{2}{*}{$0.68(0.44-1.07,0.093)$} & $89,23.0$ & \multirow[t]{2}{*}{$0.68(0.49-0.94,0.011)$} \\
\hline & Non-VHD & $52,13.5$ & & $119,30.8$ & \\
\hline
\end{tabular}

Abbreviations: NOACs, non-vitamin K oral anticoagulants; VHD, valvular heart disease; VKAs, vitamin K antagonists.

anticoagulants was less common in the study by Basaran et al than in our study. Potential explanation may be found in the differing prevalence of selected risk factors, that is, hypertension and prior stroke, among the two study populations.

The question of the choice of anticoagulant in patients with type 2 VHD remains open. As patients with moderatesevere mitral stenosis or mechanical prosthetic heart valve are at very high thromboembolic risk and have been excluded from phase III trials on NOACs compared with VKAs, these patients should continue to be treated with VKAs. However, several patients with AF and different types of VHD (i.e., moderate-severe mitral or aortic regurgitation, moderate-severe aortic stenosis) or biologic prosthetic valves have been included in these trials. For example, patients with prior valve surgery (with exclusion of mechanic valves) were excluded from RE-LY, but totalled $5.3 \%$ of the overall ROCKET-AF population, $5.2 \%$ of ARISTOTLE, and $11.5 \%$ of ENGAGE-AF. In a recent meta-analysis of these trials, the incidence of stroke or systemic embolism in patients treated with NOACs was lower than that observed in those receiving VKAs both in patients with (relative risk [RR]: 0.70, 95\% CI:
0.58-0.86) and without VHD (RR: $0.84,95 \%$ CI: 0.75-0.95). ${ }^{8}$ Similar rates of major bleeding in patients receiving NOACs or VKAs were also observed in patients with (RR: $0.93,95 \%$ CI: 0.68-1.27) and without VHD (RR: 0.85, 95\% CI: 0.701.02). A significant reduction of intracranial bleedings was also observed in the NOACs group independently of VHD status (RR: $0.47,95 \% \mathrm{CI}: 0.24-0.93$ and RR: $0.49,95 \% \mathrm{CI}$ : $0.41-059$, in patients with and without VHD, respectively). ${ }^{8}$

In a post-hoc analysis of ARISTOTLE, trial outcomes were compared according to type of VHD. ${ }^{16}$ Overall, aortic stenosis was associated with a higher risk of stroke/systemic embolism, bleeding, and death. The efficacy and safety benefits of apixaban compared with warfarin were consistent, regardless of the presence of mitral or aortic regurgitation, and aortic stenosis.

In AF patients with bioprosthetic heart valves, the evidence is scarce. A small prospective, open-label pilot study randomized AF patients with a bioprosthetic heart valve, implanted at least 3 months before randomization, to receive dabigatran (at a dose of $110 \mathrm{mg}$ twice daily) or warfarin (dose-adjusted international normalized ratio: 2-3). After 
3 months of follow-up, the incidence of intracardiac thrombus detected by transesophageal echocardiography did not differ between the two groups. ${ }^{17}$

Taken together, the results of the above trials influenced the recent American ${ }^{18}$ and European VHD guidelines. ${ }^{19-21}$ For the majority of potential clinical scenarios, there is a remarkable degree of consistency between AHA/ACC and ESC/EACTS guidelines as far as the management of patients with VHD and AF is concerned. Both societal documents consistently contend that the term "nonvalvular AF" is poorly defined and should be abandoned. Rather, the clinician should consider AF in the context of the specific VHD type and also in relation to the patient risk profile. ${ }^{22}$

A recent consensus document endorsed by several scientific societies proposed a functional EHRA categorization in relation to the type of oral anticoagulant use in patients with AF. EHRA type 1 VHD, which refers to AF patients with "VHD needing therapy with a VKA" and EHRA type 2 VHD, which refers to AF patients with "VHD needing therapy with a VKA or a non-VKA oral anticoagulant" also taking into consideration $\mathrm{CHA}_{2} \mathrm{DS}_{2}$-VASc score risk factor components. ${ }^{7}$ More recently, a practical guide on the use of non-VKA oral anticoagulants issued by the European Heart Rhythm Association, in patients with biological valves or after valve repair, stated that "the use of a NOAC for the management of concomitant AF is considered to be a valid option." However, in patients with biological mitral prosthesis implanted for rheumatic mitral stenosis and large and severely diseased atria, VKAs may still remain a valid option, although more data are needed. ${ }^{21}$

Our study was conducted in patients with EHRA type 2 VHD, for whom no clear preference emerged between VKAs and NOACs in clinical trials. During the study period, there was not enough data regarding the safety and efficacy profile of NOACs or VKAs in AF and type 2 VHD. However, we found that the presence of VHD clearly affected decision making for anticoagulation in these patients with AF. The likelihood of anticoagulant treatment before and after the registry entry visit was consistently higher in patients with type 2 VHD than in those without VHD; moreover, type 2 VHD patients were more likely to receive VKAs when compared with patients without VHD.

The present study has several limitations that are quite common in the analysis of observational studies. First, similarly to other observational studies, the risk of selection bias in the treatment allocation to VKAs or NOACs is inherent and cannot be excluded. To overcome this limitation, we propensity matched patients with type 2 VHD with those without VHD. Second, the present analysis was cross-sectional, and not intended to investigate the long-term risk of thromboembolic and bleeding complications in relation to the choice of anticoagulant in the two groups. At last, no bioprosthetic valves (including TAVI) or previous valve repairs were reported in the included population.

\section{Conclusion}

A notable finding of our study was the large proportion of patients on anticoagulants, which exceeded $90 \%$, regardless of the presence of type 2 VHD. However, VKAs remained the preferred treatment option in patients with type 2 VHD. Controlled trials between VKAs and NOACs, properly stratified by type of VHD, are definitely needed to support evidencebased clinical decisions in this special patient population.

\section{Authors' Contributions}

M.C.V. has made substantial contributions to all of the following: (1) the conception and design of the study, or acquisition of data, or analysis and interpretation of data; (2) drafting the article or revising it critically for important intellectual content; (3) final approval of the version to be submitted.

G.R. has made substantial contributions to all of the following: (1) the conception and design of the study, or acquisition of data, or analysis and interpretation of data; (2) drafting the article or revising it critically for important intellectual content; (3) final approval of the version to be submitted.

G.A. has made substantial contributions to all of the following: (1) the conception and design of the study, or acquisition of data, or analysis and interpretation of data; (2) drafting the article or revising it critically for important intellectual content; (3) final approval of the version to be submitted.

P.V. has made substantial contributions to all of the following: (1) the conception and design of the study, or acquisition of data, or analysis and interpretation of data; (2) drafting the article or revising it critically for important intellectual content; (3) final approval of the version to be submitted.

Funding

Supported in part from the no-profit "Fondazione Umbria Cuore e Ipertensione-ONLUS," Perugia, Italy.

\section{Conflict of Interest}

P.V. has received consultant or speaker fees from Boehringer-Ingelheim, Bayer, BMS-Pfizer, and Daiichi-Sankyo. G.A. has received consultant or speaker fees from Bayer, BMS-Pfizer, and Daiichi-Sankyo. The other authors declare no conflict of interest.

\section{References}

1 Menezes AR, Lavie CJ, DiNicolantonio JJ, et al. Atrial fibrillation in the 21st century: a current understanding of risk factors and primary prevention strategies. Mayo Clin Proc 2013;88(04):394-409

2 Nkomo VT, Gardin JM, Skelton TN, Gottdiener JS, Scott CG, Enriquez-Sarano M. Burden of valvular heart diseases: a population-based study. Lancet 2006;368(9540):1005-1011

3 Petty GW, Khandheria BK, Whisnant JP, Sicks JD, O'Fallon WM, Wiebers DO. Predictors of cerebrovascular events and death among patients with valvular heart disease: a population-based study. Stroke 2000;31(11):2628-2635

4 Fleming HA, Bailey SM. Mitral valve disease, systemic embolism and anticoagulants. Postgrad Med J 1971;47(551):599-604

5 Wolf PA, Dawber TR, Thomas HE Jr, Kannel WB. Epidemiologic assessment of chronic atrial fibrillation and risk of stroke: the Framingham study. Neurology 1978;28(10):973-977

6 Eikelboom JW, Connolly SJ, Brueckmann M, et al; RE-ALIGN Investigators. Dabigatran versus warfarin in patients with mechanical heart valves. N Engl J Med 2013;369(13):1206-1214 
7 Lip GYH, Collet JP, de Caterina R, et al. Antithrombotic Therapy in Atrial Fibrillation Associated with Valvular Heart Disease: Executive Summary of a Joint Consensus Document from the European Heart Rhythm Association (EHRA) and European Society of Cardiology Working Group on Thrombosis, Endorsed by the ESC Working Group on Valvular Heart Disease, Cardiac Arrhythmia Society of Southern Africa (CASSA), Heart Rhythm Society (HRS), Asia Pacific Heart Rhythm Society (APHRS), South African Heart (SA Heart) Association and Sociedad Latinoamericana de Estimulación Cardíaca y Electrofisiología (SOLEACE). Thromb Haemost 2017;117(12):2215-2236

8 Renda G, Ricci F, Giugliano RP, De Caterina R. Non-vitamin K antagonist oral anticoagulants in patients with atrial fibrillation and valvular heart disease. J Am Coll Cardiol 2017;69(11):1363-1371

9 Ruff CT, Giugliano RP, Braunwald E, et al. Comparison of the efficacy and safety of new oral anticoagulants with warfarin in patients with atrial fibrillation: a meta-analysis of randomised trials. Lancet 2014;383(9921):955-962

10 Verdecchia P, Angeli F, Bartolini C, et al. Safety and efficacy of nonvitamin K oral anticoagulants in non-valvular atrial fibrillation: a Bayesian meta-analysis approach. Expert Opin Drug Saf 2015;14 (01):7-20

11 Giustozzi M, Vedovati MC, Verdecchia P, et al. Vitamin K and nonvitamin $\mathrm{K}$ antagonist oral anticoagulants for non-valvular atrial fibrillation in real-life. Eur J Intern Med 2016;33:42-46

12 Austin PC. An introduction to propensity score methods for reducing the effects of confounding in observational studies. Multivariate Behav Res 2011;46(03):399-424

13 Austin PC. Balance diagnostics for comparing the distribution of baseline covariates between treatment groups in propensityscore matched samples. Stat Med 2009;28(25):3083-3107

14 Camm AJ, Accetta G, Ambrosio G, et al; GARFIELD-AF Investigators. Evolving antithrombotic treatment patterns for patients with newly diagnosed atrial fibrillation. Heart 2017;103(04): 307-314

\section{Appendix A: Umbria-Fibrillazione Atriale Study}

Steering Committee: Giancarlo Agnelli; Giuseppe Ambrosio; Fabio Angeli; Claudio Cavallini; Adriano Murrone; Gianpaolo Reboldi; Paolo Verdecchia (Chairperson); Gianluca Zingarini.

No-profit Sponsor: Fondazione Umbra Cuore e Ipertensione-ONLUS.

Scientific Secretary: Fabio Angeli.

Participating Investigators: Hospital of Ancona and University of Ancona, Department of Cardiology (A. Capucci, F. Guerra, G. Ciliberti); Hospital of Ascoli Piceno, Department of Cardiology (L. Moretti, P. Marchese, F. Gennaro, G. Mazzotta); Hospital of Fabriano, Department of Cardiology (S. Coiro, M. Politano, P. Scipione); Hospital of Amelia, Department of Cardiology (M.L. Suadoni, S. Bergonzini); Hospital of Assisi, Department of Medicine (P. Verdecchia, G. Molini, A. Aita); Hospital of Branca, Department of Medicine (S. Radicchia, O. Cazzato); Hospital of Branca, Department of Cardiology (E. Capponi, D. Cosmi, G. Mazzotta); Hospital of Branca, Department of Neurology (D. Giannandrea); Hospital of Città di Castello, Department of Neurology (S. Ricci, M.R. Condurso, L. Greco); Hospital of Città di Castello, Department of Cardiology (A. Murrone, A. Contine, L. Marinacci, K. Mboumi); Hospital
15 Başaran Ö, Dogan V, Beton O, et al; and Collaborators. Impact of valvular heart disease on oral anticoagulant therapy in non-valvular atrial fibrillation: results from the RAMSES study. J Thromb Thrombolysis 2017;43(02):157-165

16 Vinereanu D, Wang A, Mulder $\mathrm{H}$, et al. Outcomes in anticoagulated patients with atrial fibrillation and with mitral or aortic valve disease. Heart 2018;104(15):1292-1299

17 Durães AR, de Souza Roriz P, de Almeida Nunes B, et al. Dabigatran versus warfarin after bioprosthesis valve replacement for the management of atrial fibrillation postoperatively: DAWA pilot study. Drugs R D 2016;16(02):149-154

18 Nishimura RA, Otto CM, Bonow RO, et al. 2017 AHA/ACC Focused Update of the 2014 AHA/ACC Guideline for the Management of Patients with Valvular Heart Disease: a report of the American College of Cardiology/American Heart Association Task Force on Clinical Practice Guidelines. J Am Coll Cardiol 2017;70(02): 252-289

19 Baumgartner H, Falk V, Bax JJ, et al; ESC Scientific Document Group. 2017 ESC/EACTS Guidelines for the management of valvular heart disease. Eur Heart J 2017;38(36):2739-2791

20 Gorenek B, Boriani G, Dan GA, et al; ESC Scientific Document Group. European Heart Rhythm Association (EHRA) position paper on arrhythmia management and device therapies in endocrine disorders, endorsed by Asia Pacific Heart Rhythm Society (APHRS) and Latin American Heart Rhythm Society (LAHRS). Europace 2018;20(06):895-896

21 Steffel J, Verhamme P, Potpara TS, et al; ESC Scientific Document Group. The 2018 European Heart Rhythm Association Practical Guide on the use of non-vitamin K antagonist oral anticoagulants in patients with atrial fibrillation. Eur Heart J 2018;39(16):1330-1393

22 Erwin JP III, Iung B. Current recommendations for anticoagulant therapy in patients with valvular heart disease and atrial fibrillation: the ACC/AHA and ESC/EACTS Guidelines in Harmony...but not Lockstep!. Heart 2018;104(12):968-970

of Castiglione del Lago (C. Dembech, N. Sacchi, M. Guerrieri, M. Martinelli); Hospital of Perugia and University of Perugia, Medicina Interna e Vascolare (G. Agnelli, M.G. De Natale, C. Becattini, M.C. Vedovati); Hospital of Perugia and University of Perugia, Cardiologia e Fisiopatologia Cardiovascolare (G. Ambrosio, F. Angeli, D. Turturiello, F. Scavelli, M. Reccia, G. Giuffrè); Hospital of Perugia and University of Perugia, Medicina Interna (M. Pirro, V. Bianconi, A. Labate); Hospital of Perugia, Struttura Complessa di Cardiologia (C. Cavallini, G.L. Zingarini, F. Notaristefano, C. Riccini); Hospital of Perugia, Struttura Complessa di Pronto Soccorso (P. Groff, V. Mommi); Hospital of Foligno, Struttura Complessa di Cardiologia (G. Bagliani, C. Andreoli, C. Mangialasche); Hospital of Orvieto, Struttura Complessa di Cardiologia (R. Di Cristofaro); USL Umbria 1, Cardiologia Ambulatoriale 1 (M.G. Pinzagli); USL Umbria 2, Cardiologia Ambulatoriale 2 (L. Filippucci, A. Faleburle); USL Umbria 2, Cardiologia Ambulatoriale (S. Repaci), USL Umbria 2, Cardiologia Ambulatoriale (G. Proietti); Hospital Media Valle del Tevere, Struttura Complessa di Medicina (U. Paliani, C. Fuoco, M.G. Conti, A. Cardona, C. Bartolini); Hospital of Narni, Struttura Complessa di Medicina (P. Rinaldi), Hospital of Terni, Struttura Complessa di Cardiologia (G. Carreras, E. Boschetti, C. Poltronieri, A. Crocetti, G. Tilocca, G. Khoury); Hospital of Terni, Medicina Interna (G. Vaudo, G. Pucci, L. Sanesi, R. Sgariglia, S. Alessio, A. Cerasari, I. Dominioni). 